\title{
Natural Pineapple Leaf Fibre Extraction On Josapine And Morris
}

\author{
Muhammad Firdaus Mazalan *,Yusri Yusof \\ Faculty of Mechanical \& Manufacturing, Universiti Tun Hussein Onn Malaysia
}

\begin{abstract}
The pineapple's leaf plant contains approximately $2.5 \%$ to $3.5 \%$ of strong white silky fibres. These fibres are useful and can be extracted from the leaves. There are a few ways to extract the fibre such as hand scrapping and by extraction machine. The objective of this research is to study the quality of fibre extraction by using different age of pineapple leaf. Next, the study aims to compare the quality of Josapine and Morris pineapple leaf with tensile test. Fibre yield percentage are calculated to determine which type of pineapple leaf produce high production of dry fibre. The mechanical properties of the fibres are analysed by Tensile Test under American Standard Testing Methods (ASTM C1577-03) and Scanning Electron Microscope (SEM). The result of the fibre yield percentage show the Josapine type on 12 month ages are the highest value fibre yield percentage which is $7.89 \%$. Based on fibre yield percentages, it showed the Josapine type produce better dry fibre production compare to Morris type. Based on mechanical test, it showed Josapine type on 12 months ages are the strongest fibre compare to Morris type since it can withstand on $67.6 \mathrm{~N}$ of load.
\end{abstract}

\section{Introduction}

Pineapple is always use as food or desert as it is one of the famous local fruit. Mostly of the people who eat pineapple usually take the fruit and the seeds. Usually, pineapple leaf not in use and the leaves are disposed by burning or decomposed [1].

This research is focused on choose the suitable age for pineapple leaf fibre. In Malaysia, there are two types of pineapple are famous for plantation are Josapine (well-known for Johor-Sarawak-Pineapple) and Morris, which also known as Mauritius. These two types of pineapple leaf have different physical characteristic from each other. Josapine usually long and has more width than Morris [2]. Morris type are thornier and the Moris's fruit usually cheaper than Josapine. The rising of pineapple plantation around the world, human found the pineapple leaf fibre can be utilized for many purposes in different sectors of industries. The product that have be made from pineapple leaf is traditional cloth.

From the rising of pineapple plantation across the world, the pineapple leaf fibres are also being utilized for many purposes in different sectors of industries [3]. Besides, some research found the uses of pineapple leaf and there are many benefits for human use. From the research found, there are fibre in the pineapple leaf. Before this, the fibre from plant leaf

*Corresponding author: firdausmazalan23@gmail.com 
are from banana [4]. Environmental awareness, new laws, and legislation are forcing industries to find new materials which are environmental friendly.

The objective of this paper is to study the quality of fibre extraction by using different age of pineapple leaf. Secondly, to compare the quality of Josapine and Morris pineapple leaf with tensile test.

\subsection{Natural fibre}

Natural fibre is a fibre that comes from the nature such as mineral fibre, animal fibre and vegetables fibre. Pineapple leaf fibre also is one of the vegetable fibres. Nowadays, the source from petroleum products is very limited and uncertain [5]. From this problem, many industry and research decided to find an alternative way with a cheap sustainable. Other than that, the alternative way also must be a source that easily available raw material.

For information, many developing countries trade lignocellulosic fibres for economic improvement. This method also can help the poor farmers as much the support from the country. Other than agricultural propose, the countries growing the plant to generate raw materials for industries. The polymer composited that containing cellulosic fibres are being under focus in the literature recently.

There are around 30 million tonnes of natural fibres that are produced every year [5]. Usually, the source of natural fibres is being used as a component in many manufacturing processes such as packaging, clothing, automobiles, sports equipment, paper making and building materials [6]. Besides that, natural fibres composites get the attention to industry due its eco-friendly nature compare traditional composites and density [7].

Basically, there are two types of retting process which is dry retting and water retting [8]. The water retting is widely used in Asian countries. The quality of dry retting usually not good as water retting. However, dry retting is most popular used in Europe. Natural fibres are divided into three major structural parts and have systematic internal cell wall structures [9].

\section{Fibre yield percentage}

The percentage yield of pineapple fibre is to measure the total fibre that can produce from each leaf. Both Josapine and Moris were extracted by using an extractor machine called Pinapple Leaf Fiber Machine 1 (PALF M1) and then were dried under the sun for two days. Figure 1 show the pineapple leaf fibre machine (PALF M1). From production of fibres, there are three states in this research. The state of the fibre is wet fibre, dried fibre and usable fibre. When fibres are freshly extracted from original leaf, it contains a moisture and the name is wet fibre [2].

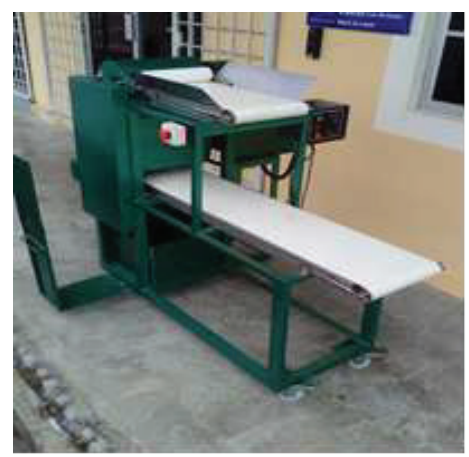

Figure 1: Pineapple leaf fibre machine (PALF M1) 
The dried fibre is when the fibre is dried under sunlight or certain temperature after extracted from it leaf. Furthermore, the usable fibre is the total weight of dried fibre that are divided by the original weight of fibre [2]. From each types of pineapple leaf divided into three ages which is 4,8 and 12 months. For the test to be success, 5 pieces of leaf from each type of pineapple leaf are used.The percentage yield of pineapple fibre can be calculated by using equation (1).

$$
\text { fibre yield }(\%)=\frac{\text { Weight of dry palf }(\mathrm{kg})}{\text { Weight of fresh pineapple loaf }(\mathrm{kg})} \times 100 \%
$$

Hence, the fibre yield projected from this equation will determine which type of pineapple leaf have the highest percentage of fibre yield.

After done with weighing process of dried fibre, the selected leaf then extracted, dried and the results for the fibre yield analysis test were shown in Figure 2.

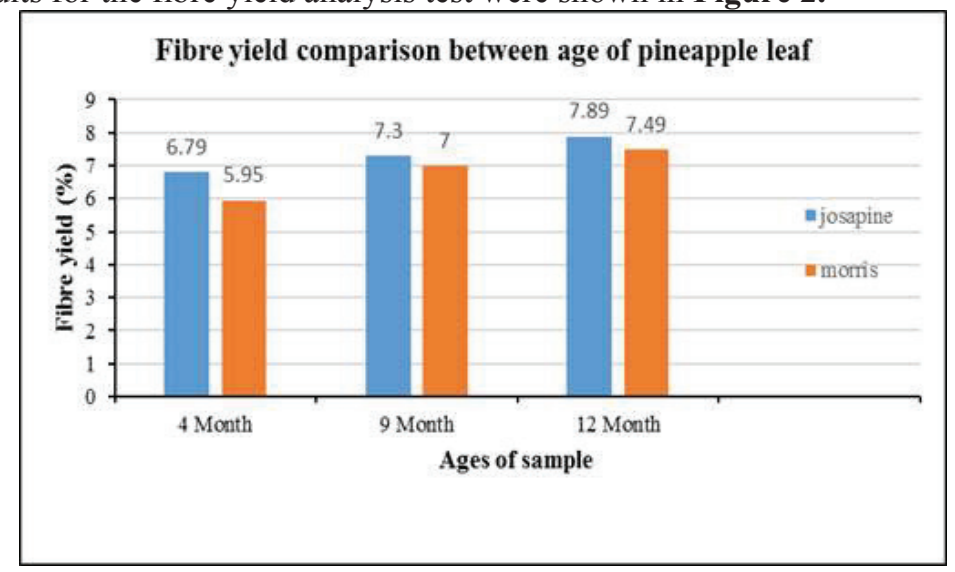

Figure 2: Average fibre yield percentage between ages of pineapple leaf

According to Figure 2, the highest fibre yield percentage for Josapine is $7.89 \%$ for 12 month samples and the highest fibre yield percentage for Morris is $7.49 \%$ on 12 month samples. For the Josapine type, it can give a conclusion fibre yield on 12 months with $7.89 \%$ is higher than 4 and 8 month samples which is $6.79 \%$ and $7.30 \%$. The same result also happened on Morris type which is 12 month samples with $7.49 \%$ is higher than 4 and 8 month samples which is $5.95 \%$ and $7.00 \%$.

For the overall, Josapine type for fibre yield percentage have higher than Morris type due to leaf size and even easier to be extracted. As conclusion, the best production of fibre between Josapine and Morris is Josapine as it gives the highest fibre yield percentage compare to Morris type. For the best ages in choosing pineapple leaf to get the highest maximum percentage yield, the most suitable age is 12 months age compare to 4 and 8 months.

\section{Tensile Test Analysis}

The objective of tensile test is to measure the extent to which the fibre or specimen sample can elongate to the breaking point. In other words, tensile test need to measure which force need to break the fibre or specimen sample. In this test, two types of pineapple leaf fibre are used which is Josapine and Morris type. Furthermore, each type of samples divided into different age such as 4,8 and 12 months.

For the test to be success, 5 pieces of leaf from each type of pineapple leaf are used. The standard used for the testing was based on American Standard Testing Methods 
(ASTM C1577-03). Figure 3 show the graph for the comparison average fibre yield percentage between ages of pineapple leaf.

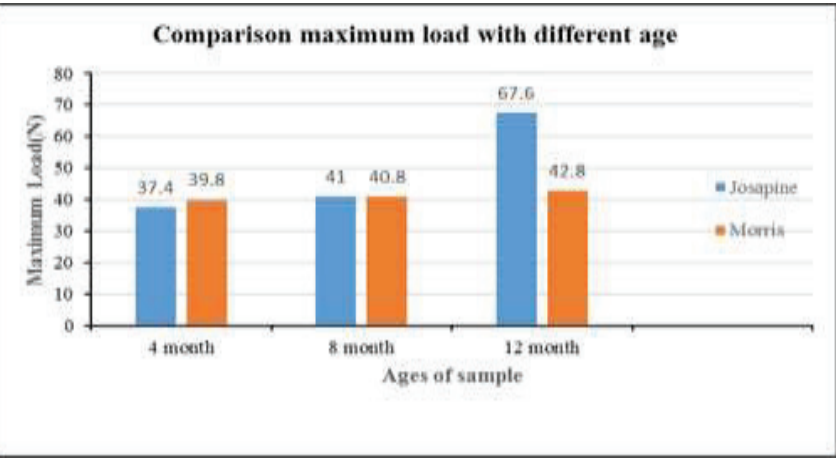

Figure 3: Comparison maximum load between ages and type of pineapple leaf

Based on Figure 3, the highest of the maximum load for Josapine type is $67.6 \mathrm{~N}$ for 12 months and the highest maximum load for Morris type is $42.8 \mathrm{~N}$ on 12 months. For the overall on Josapine type, it can give a conclusion maximum load value on 12 months with $67.6 \mathrm{~N}$ is higher than 4 and 8 months which is $37.4 \mathrm{~N}$ and $41 \mathrm{~N}$. Meanwhile, the same result also happened on Morris type which is 12 month samples with $42.8 \mathrm{~N}$ is higher than 4 and 8 month samples which is $39.8 \mathrm{~N}$ and $40.8 \mathrm{~N}$.

Next for 8 month samples between Josapine and Morris type, there are only small different which is $0.02 \mathrm{~N}$ between this two type of pineapple leaf. The result might be the same as the thickness of the fibre samples between Josapine and Morris type on 8 months have small difference value compare to another sample which is 4 and 12 month samples.

Furthermore, the maximum load value for Morris type higher than Josapine for 4 month samples. The result might be affected because the thickness of the fibre sample of Morris is bigger than Josapine type. Next, the lowest value of maximum load is from Josapine on 4 month samples with $37.4 \mathrm{~N}$.

From the overall sample between age and type of pineapple leaf, the best and the stronger fibres since it has higher maximum load value is Josapine type with $67.6 \mathrm{~N}$. Meanwhile, the stronger fibres based on age and is 12 month ages.

\section{Morphological Analysis}

Fibre structure can be studied by using Scanning Electron Microscope (SEM) machine. From this test, it can analyse the surface structure of the pineapple leaf fibre. In this test, there are six samples which is three sample from Josapine type and three sample from Morris type. The samples are divided based on their age which is 4, 8 and 12 month ages. Each sample from the type of pineapple leaf fibre are chosen from the highest value of fibre yield percentage. Figure 4 show the surface structure for different ages and type of pineapple leaf fibre.

From figure Figure 4, it is apparent that the pineapple leaf fibre extracted using PALF M1 produces parallel fibre arrangement. Meanwhile, the surface structure for 4 month ages show Josapine type is more attractive and clean in producing dry fibre after extraction process compare to Morris type.

Other than that, the surface structure for 8 month ages show the same result as 4 month samples which is Josapine type is more clean compare to Morris. Based on 8 month Morris sample, the surface structure not clean enough after extraction process since Morris leaf surface more thicker compare to Josapine type. 


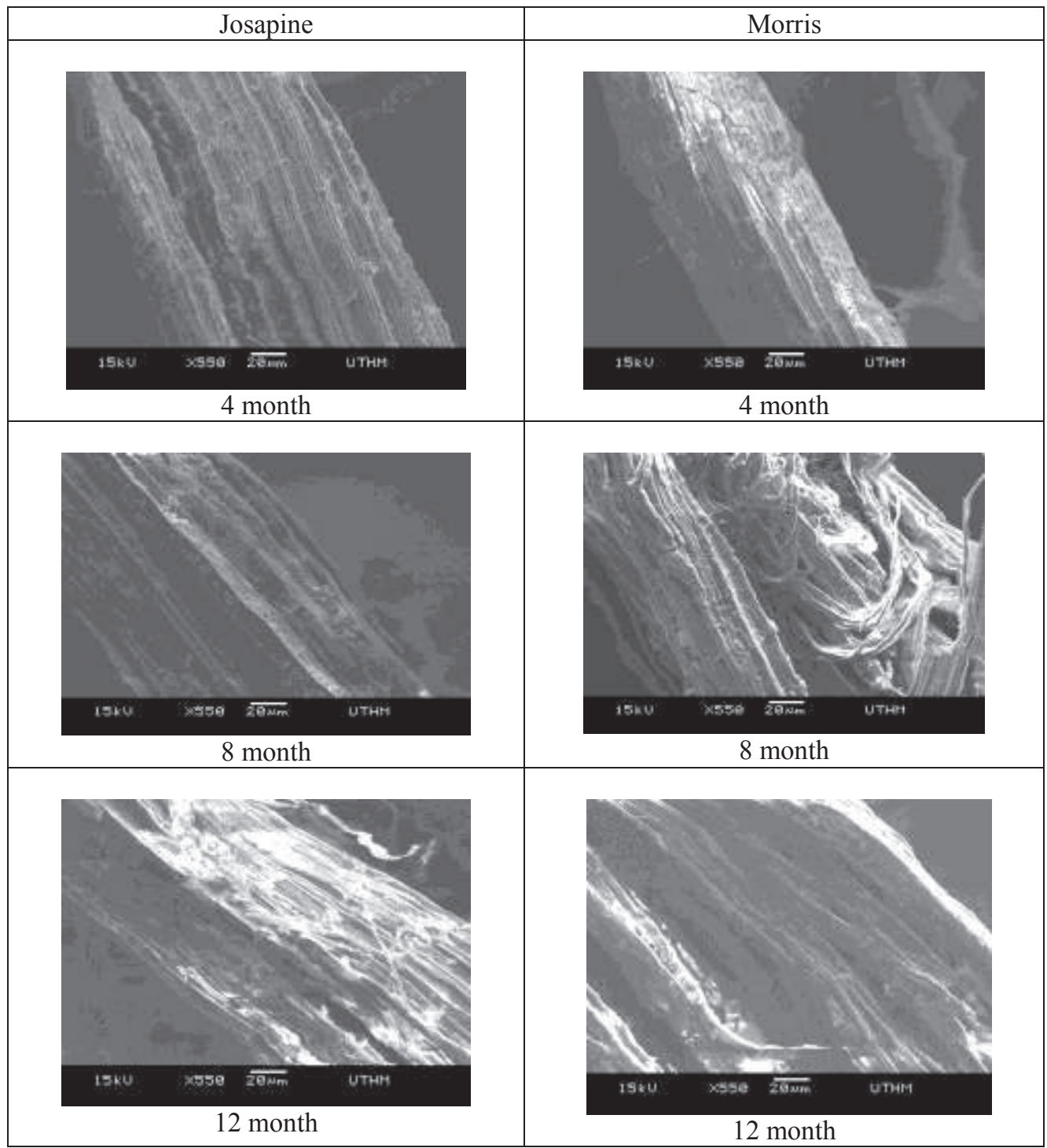

Figures 4: SEM Images of structure at 550x magnification of Pineapple leaf fibre

Finally, the surface structure for 12 month show the Josapine type produce more fibre and completely extracted compare to Morris type. For the overall, pineapple leaf fibre from Josapine type produce better quality compare to Morris as Josapine leaf easier to be extracted [2].

\section{Conclusion}

For the development and improvement in pineapple leaf fibre usage across the country, it is important to determine which type of pineapple leaf better. From the test and analysis, it can be said Josapine type more better than Morris type since it has the more 
fibre, strong and easier to be extracted. Other than that, Josapine fruit's price higher than Morris so Josapine type more suited type to be grown in agriculture sector.

\section{References}

[1] Y. Yusof, S. A. Yahya, and A. Adam, "A New Approach for PALF Productions and Spinning System: The Role of Surface Treatments," vol. 1, no. 2, pp. 161-164, 2014.

[2] A. Adam and A. Yahya, "Extraction of Pineapple Leaf Fiber : Josapine and Moris," vol. 11, no. 1, pp. 161-165, 2016.

[3] D. B. Dittenber and H. V. S. G. Rao, "Critical review of recent publications on use of natural composites in infrastructure," in International SAMPE Technical Conference, 2011.

[4] R. M. N. Arib, S. M. Sapuan, M. M. H. M. Ahmad, M. T. Paridah, and H. M. D. K. Zaman, "Mechanical properties of pineapple leaf fibre reinforced polypropylene composites," Mater. Des., vol. 27, no. 5, pp. 391-396, 2006.

[5] M. Asim et al., "A Review on Pineapple Leaves Fibre and Its Composites," Int. J. Polym. Sci., vol. 2015, pp. 1-17, 2015.

[6] M. Jawaid and H. P. S. Abdul Khalil, "Cellulosic/synthetic fibre reinforced polymer hybrid composites: A review," Carbohydrate Polymers, vol. 86, no. 1. pp. 1-18, 2011.

[7] M. Drzal, L. T., Mohanty, A. K., \& Misra, "Bio-Composite Materials As Alternatives To Petroleum-Based Composites for Automotive Applications," Magnesium, vol. 40, pp. 1-3, 2001.

[8] J. Foulk, D. Akin, R. Dodd, and D. McAlister III, "Flax fiber: potential for a new crop in the Southeast," Trends new Crop. new uses, no. December 2015, pp. 361370, 2002.

[9] B. Madsen, "Properties of Plant Fibre Yarn Polymer Composites," Thesis, p. 218, 2004.

[10] D. N. Saheb, J. P. Jog, D. Nabi Saheb, and J. P. Jog, "Natural Fiber Polymer Composites : A Review," Adv. Polym. Technol., vol. 18, no. 4, pp. 351-363, 1999.

[11] A. K. Bledzki and J. Gassan, "Composites reinforced with cellulose based fibres," Prog. Polym. Sci., vol. 24, no. 2, pp. 221-274, 1999.

[12] M. J. John and R. D. Anandjiwala, "Recent developments in chemical modification and characterization of natural fiber-reinforced composites," Polym. Compos., vol. 29, pp. 187-202, 2008. 